OPEN ACCESS

Edited by:

Richard Hamelin,

University of British Columbia

Canada

Reviewed by:

Giorgio Maresi,

Fondazione Edmund Mach, Italy Kayla I. Perry,

The Ohio State University,

United States

*Correspondence:

Stefan Klesse

Stefan.klesse@wsl.ch

Specialty section:

This article was submitted to

Pests, Pathogens and Invasions,

a section of the journal

Frontiers in Forests and Global

Change

Received: 24 December 2020

Accepted: 01 March 2021

Published: 22 March 2021

Citation:

Klesse S, Abegg M, Hopf SE,

Gossner MM, Rigling A and Queloz V (2021) Spread and Severity of Ash

Dieback in Switzerland - Tree

Characteristics and Landscape

Features Explain Varying Mortality

Probability.

Front. For. Glob. Change 4:645920.

doi: 10.3389/ffgc.2021.645920

\section{Spread and Severity of Ash Dieback in Switzerland - Tree Characteristics and Landscape Features Explain Varying Mortality Probability}

\author{
Stefan Klesse ${ }^{1,2 *}$, Meinrad Abegg ${ }^{2}$, Sven E. Hopf ${ }^{3}$, Martin M. Gossner ${ }^{1,4}$, \\ Andreas Rigling ${ }^{4,5}$ and Valentin Queloz ${ }^{1}$
}

\begin{abstract}
${ }^{1}$ Forest Health and Biotic Interactions, Swiss Federal Research Institute for Forest, Snow, and Landscape Research WSL, Birmensdorf, Switzerland, ${ }^{2}$ Forest Resources and Management, Swiss Federal Research Institute for Forest, Snow, and Landscape Research WSL, Birmensdorf, Switzerland, ${ }^{3}$ Institute for Applied Plant Biology, Witterswil, Switzerland, ${ }^{4}$ Department of Environmental Systems Science, Institute of Terrestrial Ecosystems, ETH Zürich, Zurich, Switzerland, ${ }^{5}$ Forest Dynamics, Swiss Federal Research Institute for Forest, Snow, and Landscape Research WSL, Birmensdorf, Switzerland
\end{abstract}

Since the 1990s the invasive fungus Hymenoscyphus fraxineus has been threatening European ash (Fraxinus excelsior), a tree species with high ecological and economic importance. This pathogen is causing severe crown dieback, leading to high mortality rates across Europe and is present in Switzerland since 2008. In this study, we provide a comprehensive overview of the temporal evolution of crown damage and mortality rates in Switzerland over the 2009-2019 period. Harnessing the power of the annualized design of the Swiss national forest inventory (NFI), we show that annual mortality rates (AMRs) of ash increased significantly since the arrival of the fungus, with stronger effects in small trees $[<26 \mathrm{~cm}$ diameter at breast height $(\mathrm{DBH})]$. Mortality modeling confirmed a size and growth-rate dependent mortality probability (MP). It also revealed that stands with higher humidity - either through higher mean annual precipitation or more humid soil conditions - showed also increased MP. Decreasing host abundance with increasing elevation was also associated with lower MP. Special ash surveys performed over the last 10 years still show a large percentage of ash trees with very low defoliation. This gives hope to finding possible tolerant or resistant trees for (inter-)national breeding programs. In the mean-time our results reinforce previously published management guidelines to promote not only healthy big trees, but also healthy and fast-growing young trees in more open stands for long-term conservation of ash in Europe.

\section{Keywords: Hymenoscyphus fraxineus, mortality, defoliation, national forest inventory, mortality model, tree health assessment, invasive pathogen, European ash}

\section{INTRODUCTION}

Invasive species represent an increasing challenge for forest and tree health globally (Holmes et al., 2009; Moser et al., 2009; Pyšek and Richardson, 2010; Trumbore et al., 2015). Moreover, some invasive pathogens can lead to near extinction of tree species and threaten whole ecosystems and their functioning (Pautasso et al., 2015). A prominent example is Ash dieback (ADB) in Europe. 
ADB is caused by the ascomycete Hymenoscyphus fraxineus (Baral et al., 2014) native to Eastern Asia (NE China, Korea, and Japan). First symptoms resembling late frost were observed in the early 1990s in north-eastern Poland and Lithuania (Kowalski and Łukomska, 2005; Cleary et al., 2016; Gil et al., 2017). Since then the disease has spread fast (around $75 \mathrm{~km} /$ year) and is now threatening European ash (Fraxinus excelsior) populations throughout Europe (Gross et al., 2014). The wind-dispersed pathogen spreads through ascospores, formed on old rachises of ash in the litter, that infect leaves in summer and cause necrotic lesions that lead to early leaf wilting (Gross et al., 2014). The fungus may further spread to the xylem through the petioleshoot junction leading to dieback of shoots and twigs (Hanáčková et al., 2017). Repeated annual infections disrupt nutrient and water transport and lead to gradual crown dieback and ultimately the tree's death.

Besides its high cultural and economic values (Boshier et al., 2005; Pautasso et al., 2013) ash also is considered a keystone species for biodiversity providing critical habitat for many species (Mitchell et al., 2014; Rigling et al., 2016). Ash is a tree species phylogenetically distinct from most central European tree genera and thus characterized by a distinct and highly specialized community of associated organisms [30\% of all phytophagous insect and mite species are host specialists (Brändle and Brandl, 2001)]. As a consequence many associated species face a high risk of extinction when ash trees disappear from the European landscape (McKinney et al., 2012; Hultberg et al., 2020).

It has become evident that small trees and slow-growing trees are more vulnerable to crown dieback and subsequent mortality than big and fast-growing trees (Marçais et al., 2017; Enderle et al., 2018; Enderle, 2019; Klesse et al., 2020). Recent research has also shown that low host abundance and lesshumid microclimatic conditions negatively influence the spread and severity of the disease (Grosdidier et al., 2020). Indeed, ash trees in hedges or in forests with open canopies tend to have a microclimate with higher crown temperatures and lower humidity unfavorable to fungal spore germination and growth (Bakys et al., 2013; Hauptman et al., 2013; Marçais et al., 2016; Grosdidier et al., 2018, 2020). This is in line with findings that dieback symptoms are less severe in drier and warmer compared to more humid and cooler forest stands (Chira et al., 2017; Davydenko and Meshkova, 2017; Ghelardini et al., 2017; Heinze et al., 2017). Despite the general high impact of the pathogen on ash trees, several studies have shown that a small percentage of trees without or with only low levels of crown dieback exist even in the neighborhood of highly affected trees (Lenz et al., 2016; Hopf, 2019; Klesse et al., 2020; Menkis et al., 2020).

In Switzerland, F. excelsior is the third most abundant broadleaf tree species ( $4.4 \%$ of total stem number) and constitutes $3.8 \%$ of standing tree volume [second highest volume among broadleaf tree species, Brändli et al. (2020)]. Young trees and saplings $[<12 \mathrm{~cm}$ diameter at breast height $(\mathrm{DBH})]$ even account for $22.5 \%$ of the stem count in forest regeneration plots. However, the percentage of damaged ash regeneration area has increased from $1 \%$ (2004-2006) to $14 \%$ (2009-2017) and is even higher in the tree class with $>1.3 \mathrm{~m}$ height (30\%; Brändli et al., 2020). This increase in damaged regeneration is mainly attributed to
H. fraxineus, first observed in 2008 (Engesser et al., 2009) in the northern regions of Switzerland and ubiquitous since 2015. Several systematic and targeted forest monitoring programs have additionally tracked the disease development over time and space, also under the aspect of finding ash trees tolerant or even resistant to the fungus for future reforestation purposes (Hopf, 2019; Queloz and Gossner, 2019). In this study we harness the power of the systematic and continuous inventory design of the Swiss national forest inventory (NFI) to make an unbiased and representative assessment of the current situation of ADB in Switzerland. A continuous or rotating NFI enables a costeffective and more frequent production of representative reports on the state of forests (Schreuder et al., 1999; Fischer and Traub, 2019). In a continuous inventory data of permanent plots are not collected periodically every 10 years but each year a sub-grid covering the entire country is visited, completing the inventory after $n$ years, where $1 / n$ is the size of the sub-grid. We supplement the NFI dataset with data from specific and nonspecific (ash) monitoring programs in Switzerland. Specifically, we were interested in answering the following questions: (1) How did the annual mortality rates develop since 2008? (2) Which tree characteristics and landscape features determine the probability of mortality? (3) Do the data reveal possibilities for the F. excelsior population to overcome or recover from ADB?

\section{MATERIALS AND METHODS}

\section{Monitoring Data}

We used data from four different long-term monitoring programs: (1) The Swiss NFI, (2) targeted regional ash surveys of the Institute for Applied Plant Biology (IAP), (3) the targeted ash survey of the Swiss Federal Research Institute WSL, and (4) the Swiss long-term forest ecosystem research program LWF.

1. The NFI is conducted on a regular sampling grid in Switzerland (Fischer and Traub, 2019). It started in 1983 with a periodical design and changed in 2009 to a continuous forest inventory in which sampling takes place on a subgrid each year, completing the full grid within 9 years. The permanent sample plots consist of two concentric circles covering an area of 200 and $500 \mathrm{~m}^{2}$, respectively, in which each tally tree with a minimum DBH of $\geq 12 \mathrm{~cm}(>36 \mathrm{~cm}$ in the outer circle) is measured. This allows reconstructing each tally tree's history since its first measurement. The fourth NFI was conducted from 2009 to 2017, directly followed by the first 2 years of the fifth inventory in 2018 and 2019, revisiting plots from 2009 and 2010. Since 2009, 661 unique plots had at least one ash tree tallied (median: 2, maximum: 13). Examined plots with ash per year ranged from 43 to 103 , and surveyed ash trees ranged from 88 to 257 , totaling 1,583 unique trees. The median DBH of surveyed ash trees in the third NFI before the arrival of the fungus (20042006) was $26 \mathrm{~cm}$. The observed forest types predominantly belong to the rather wet Alno-Fraxinion group (Keller et al., 1998) in the lower elevations of Switzerland (Supplementary Figure 1) with mean annual temperatures around $8.9^{\circ} \mathrm{C}$ 
[interquartile range (IQR): $7.9-9.5^{\circ} \mathrm{C}$ ] and mean annual precipitation sums of $1,240 \mathrm{~mm}$ (IQR: 1,140-1,420 mm). True to the concept of the annualized inventory design, we did not detect systematic differences in tree size, elevation, or forest type between the individual years the inventories were conducted.

2. In 2013 and 2014, 22 European ash dominated stands in north-west Switzerland (across an area of $\sim 2,500 \mathrm{~km}^{2}$ ) were selected for observation from the IAP (Queloz et al., 2017; Hopf, 2019). At the time of selection, the disease was fully established throughout the region. In these stands, between six and ten apparently healthy trees belonging to (co-) dominant social classes were selected and visually inspected for crown transparency and disease intensity each year at the end of August. Altogether, the IAP monitored 205 trees. The median DBH at the beginning of the survey was $40 \mathrm{~cm}$. Due to the low number of trees per plot this survey - covering a rather homogeneous geographic region - was analyzed as one population in the subsequent analysis.

3. In 2011, the Swiss Federal Research Institute WSL installed three monitoring plots with varying sizes south of Zürich in ash dominated stands surveying each year 60, 104, and 40 trees, respectively (Klesse et al., 2020). Median DBH of the annually monitored trees in 2011 were 18,20 , and $43 \mathrm{~cm}$, respectively.

4. We further included one site belonging to the Swiss longterm forest ecosystem research program LWF (Etzold et al., 2014; Eichhorn et al., 2016), which is also part of the European long-term ecosystem research (LTER) and ICPforests monitoring programs. Switzerland maintains 19 sites that are regularly monitored, but only one site (site name: Schänis, size: 2 ha), located in north-eastern Switzerland, had enough ash trees $(n=83$, median DBH in 2010: $53 \mathrm{~cm})$ to be included in this analysis.

\section{Observed Mortality and Crown Damage}

Based on individual tree data, annual mortality rate $(A M R)$ was calculated for each of the four data sources and each inventory end year as:

$$
A M R=\left(1-\left(\left(\frac{N_{\Delta t}}{N_{0}}\right)^{\frac{1}{\Delta t}}\right)\right) * 100,
$$

where $N_{0}$ and $N_{\Delta t}$ are the numbers of living trees at the beginning and end of the interval, respectively, and $\Delta t$ is the inventory interval length in years (Sheil and May, 1996). Due to the switch from periodic to annualized inventory design in the NFI, subsets with different $N_{0}$ and thus different lengths $\Delta t$ were first calculated separately and then combined with a weighted average according to the abundance of observations in each subset. To detect whether mortality rates since the arrival of the pathogen are different from before, we established a baseline $A M R$ with the periodic NFI inventories ending before 2008. Therefore, and because each inventory year 2009-2017 consists of different trees, bootstrap resampling with 1,000 iterations and 133 draws with replacement (representing the lowest number of individuals in the inventory of 2009) was applied to estimate uncertainties (IQR and 2.5th and 97.5th percentile) of the mortality estimates. We also calculated $A M R$ and associated uncertainties for all non-ash trees in the investigated NFI plots and repeated this analysis for small $(<26 \mathrm{~cm} \mathrm{DBH})$ and big trees, separately. In these instances, resampling was performed with 72 and 61 samples, respectively. We did not resample the data of the other three data sources, because they consist of the same trees in each inventory year. Please note that mortality rate values for a given year in the NFI and LWF relate not to actual mortality rate in that year, but to integrated $A M R$ of the entire inventory interval. Whereas, $A M R$ in the targeted surveys (IAP and WSL plots) can be readily interpreted as trees that died in the survey year.

Concerning crown damage, we investigated the percentage of trees with considerable crown loss ( $>50 \%$ defoliation) in the inventory year. For the NFI data we applied the same uncertainty analysis as above. We also subdivided the actual targeted annually monitored trees into those with crown defoliation greater than $50 \%$ to enable comparison with the pseudo-annual NFI crown loss time series. Additionally, for the non-NFI surveys we also calculated the percentage of trees that showed little crown dieback symptoms, i.e., $<25 \%$ defoliation. This information is unavailable for the NFI plots.

\section{Modeled Mortality Probability}

We applied generalized logistic regression (Hosmer et al., 2013) to model mortality probability (MP) based on the NFI data collected from 2009 to 2019, i.e., including only observations since the arrival of the fungus in Switzerland. The MP $p$ of tree $i$ in plot $j$ at time $k$ was defined as:

$$
\operatorname{logit}\left(p_{i, j, \mathrm{k}}\right)=\log \left(\frac{p_{i, j, \mathrm{k}}}{1-p_{i, j, \mathrm{k}}}\right)=\boldsymbol{\beta} \mathbf{X}+\log (\triangle \mathbf{t})
$$

where $\boldsymbol{\beta} \mathbf{X}$ represents a linear combination of parameters $\boldsymbol{\beta}$ to be estimated and explanatory variables $\mathbf{X}$ and $\Delta \mathbf{t}$ is a vector with the inventory interval lengths $t_{i, j, k}-t_{i, j, k-1}$. This parameter is included as an offset, i.e., an independent variable whose parameter is fixed to 1 , acting as a composite interest rate upon the annual MP (Fortin et al., 2008). Because the number of observations per plot $j$ at time $k$ is very small $(\leq 2$ in $64 \%$ of all plots), we did not apply a mixed-effects model.

We used tree-, stand-, and forest district-specific variables to model MP. Tree-specific variables included $\mathrm{DBH}$ at the beginning of the inventory period ( $\mathrm{DBH}, \log$-transformed) and relative annual basal area increment (relBAI). relBAI (Bigler and Bugmann, 2004) was calculated for the inventory period preceding the period of interest as

$$
\operatorname{relBAI} I_{i, j, k}=\left(\frac{B A_{i, j, k-1}}{B A_{i, j, k-2}}\right)^{\frac{1}{\Delta t}}
$$

with $B A_{i, j}$ being the basal area of tree $i$ in plot $j$ and $\Delta$ t denoting the number of vegetation periods between observations, i.e., the inventory interval length between time $k-1$ and $k-2$. Negative increments were reset to zero. We applied a modified $\log 10$ 
transformation based on the common logarithm that is applicable even to the few observations where relBAI $=0$ (Stahel, 2019).

Stand-specific variables (as provided by the NFI) included elevation, slope steepness, slope curvature, stand density related variables such as standing basal area and basal area of larger trees, number of growing season periods between two consecutive inventories, forest type, and climate. We created a binary variable based on the forest type classification of Keller et al. (1998) to distinguish between wet and not-wet forest types. Mean annual precipitation totals and mean annual temperature were extracted from gridded and downscaled meteorological data from MeteoSwiss with a resolution of $1 \mathrm{~km}$ (MeteoSwiss, 2021).

Based on feedback of country-wide surveys and laboratory confirmed cases we determined the first year of observation of the fungus within a given forest district. For each forest district this year of first observation was subtracted from the year of the actual inventory to create a variable of fungal presence time (TIMESINCE). If the inventory pre-dated the first observation of the fungus, this variable was set to -1 .

Model selection based on the Bayesian information criterion (BIC) was performed in R ( $\mathrm{R}$ Core Team, 2018, R Version 3.5.2) using the dredge function in the MuMIn package (Bartoń, 2018), and included all possible two-way interactions. The final model structure was then applied to NFI data prior to 2008 to compare how factors influencing MP have changed with the new disease.

\section{RESULTS}

\section{Observed Crown Defoliation}

We found a significant step increase in the percentage of NFI ash trees with $>50 \%$ crown loss in 2014 from near $0-8 \%$ and another step increase to $22 \%$ in 2019 ( $p<0.001$, Figure 1). Because the different inventories 2009-2017 do not consist of the same trees, and the response variable is binary ( $>50 \%$ crown loss, yes or no) and does not account for previous crown defoliation (e.g., 5, 25, or $45 \%$ ), we caution against over-interpreting these step changes. No increase in crown damage was observed in non-ash trees at the same plots, staying $<1 \%$ in all eleven inventory years. We did not find such a step increase in the other surveys, where the percentage of alive trees with $>50 \%$ crown defoliation increased only slightly over time (Figure 2A). However, we found large differences in absolute values between surveys, ranging from $1 \%$ in 2019 in the IAP survey, specifically targeting initially resistant trees, to 17 and $33 \%$ in the two WSL plots with the smallest average $\mathrm{DBH}$ (RAM and LW1) in more vulnerable stands. In both the LWF and IAP survey more than $80 \%$ of the trees in 2019 ( $n_{\text {total }}=75$ and 189 , respectively) had still very healthy crowns with less equal or less than 25\% defoliation (Figure 2B).

\section{Observed Mortality}

We found a strong increase in $A M R$ since 2009 (Figure 3A) in the NFI data. In the beginning of the investigated period $A M R$ averaged at $0.3 \%$ and was indistinguishable from $A M R$ before the arrival of the fungus. Since 2014, $A M R$ was significantly higher than observed background mortality rates and reached $1.4 \%$ in the 2019 survey. AMR for small ash trees started around $0.4 \%$ and reached $2.0 \%$ in 2019 and was notably higher than those of big ash trees $(0.2-0.9 \%$, Figures $3 B, C)$. No trend was observed in $A M R$ of non-ash trees, which stayed rather constant at $0.7 \%$. A constant $A M R$ was also observed for the four most abundant co-occurring species Picea abies, Fagus sylvatica, Abies alba, and Acer pseudoplatanus, separately (Supplementary Figure 2).

Annual mortality rate was very low in the IAP survey and averaged $0.9 \%$ (range $0-2.6 \%$, Figure 2C). Putting this number (which is based on the 2013-2019 period) into context of 9 years (NFI 2010-2019) would return an $A M R$ of $0.6 \%$ (by adding 3 years with zero mortality in the beginning). The 11 trees that died in the IAP survey also had a much smaller DBH (median: $27 \mathrm{~cm}$; range: $12-45 \mathrm{~cm}$ ) compared to the population average of $40 \mathrm{~cm}$. Only in 2019 the first two trees belonging to the lowest quartile in DBH died in the LW2 plot. In contrast, $A M R$ in RAM and LW1 were considerably higher, resulting in very high cumulative mortality in 2019 of 72 and 35\%, respectively (Figure 2D).

\section{Modeled MP in Relation to Environmental Factors and Time of Pathogen Arrival}

We found a clear size and growth rate-dependent MP in both investigated periods (pre-ADB, with $\mathrm{ADB}$ ) with very similar logodds ratios (Table 1 and Figure 4). Small trees and relatively slow-growing trees had a much higher MP. In both periods, steeper slopes had a significant positive effect on MP. However, in wet forest types slope steepness did not influence MP. Since the arrival of the invasive fungus MP was $85 \%$ higher in wet forest types compared to normal and dry forest types. In areas with higher mean annual precipitation MP also increased, whereas in higher elevation stands MP was reduced. Both factors did not influence MP before the arrival of the fungus. Time since first observation had a significant positive effect on MP.

Compared to the time before the arrival of the fungus MP for small $(<20 \mathrm{~cm} \mathrm{DBH})$ and slow-growing trees (relBAI $<2 \%$ ) has drastically increased and was up to $55 \%$ higher in 2019 , whereas MP was relatively unchanged $(+4 \%)$ for big $(>50 \mathrm{~cm} \mathrm{DBH})$ and fast-growing trees ( $>3 \%$ relBAI, Figure 3).

\section{DISCUSSION}

In this study, we provided a comprehensive overview of crown damage and mortality rates of ash trees in Switzerland over the past 11 years. For the first time we provide a national-wide and geographically unbiased assessment of mortality rates before and after the arrival of $H$. fraxineus harnessing the power of the annualized design of the Swiss NFI. We showed that AMRs of F. excelsior are at unprecedented levels compared to observations before the arrival of the pathogen and have disproportionally increased in small and slow-growing trees. Further, our analyses confirm previous observations that mortality elevated in stands with humid microclimatic conditions and high abundance of ash trees. At the same time, we showed that in many stands there are still healthy trees seemingly tolerant to the disease. In the following, we discuss our results in the context of 


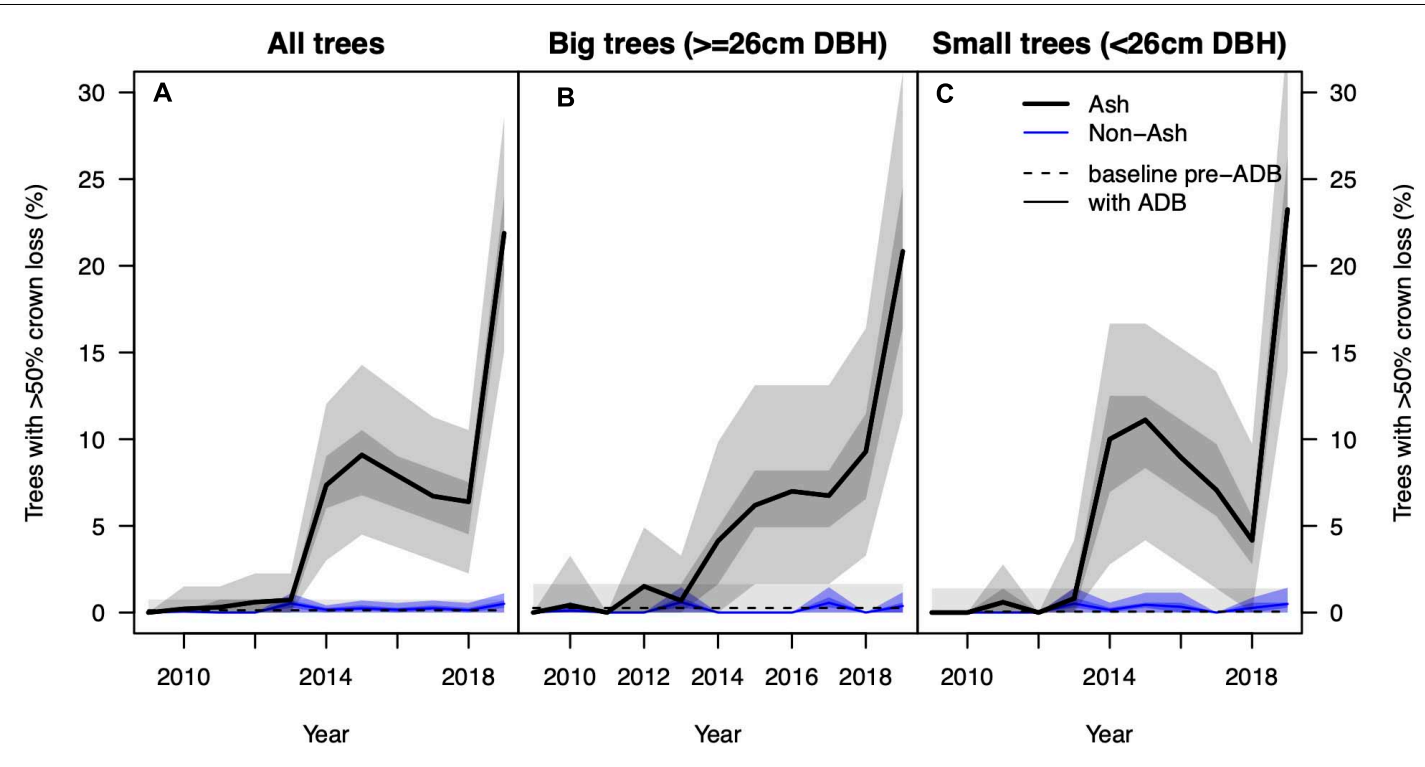

FIGURE 1 | (A) Observed percentage of ash (solid black line) and non-ash trees (blue line) with > 50\% crown loss based on data from the National Forest Inventory. The dashed black line denotes the "background" percentage of Fraxinus excelsior with $>50 \%$ crown loss before the arrival of the fungus. The shadings around the solid lines show the interquartile range (dark) and 95\% confidence interval (light) after 1,000 iterations of resampling with replacement. Panels (B,C) show the same information for big ( $\geq 26 \mathrm{~cm} \mathrm{DBH}$ ) and small trees (<26 cm DBH), respectively. Please note only the data pairs $2009 / 2018$ and $2010 / 2019$ comprise the same trees (excluding ingrowth and mortality).

other systematic (non-targeted) forest inventory and targeted monitoring literature and provide an outlook for $F$. excelsior conservation in Europe.

\section{Modeled and Observed MP}

The growth rate and size-dependent MP of F. excelsior found in the NFI (Figure 3 ) matches that of F. excelsior in forest reserves in Switzerland (Wunder et al., 2008; Hülsmann et al., 2017), Poland (Wunder et al., 2008), and Denmark (Wolf et al., 2004). For Swiss forest reserves, Hülsmann et al. (2016) reported a 2.2\% background mortality. The higher value in the forest reserves compared to our reported background mortality of $0.3 \%$ in the NFI plots can be explained by the much smaller DBH threshold ( $4 \mathrm{~cm}$ compared to $12 \mathrm{~cm}$ in the NFI) and the smaller mean DBH ( $18.7 \mathrm{~cm}$ compared to $26.6 \mathrm{~cm}$ in the NFI). A size-dependent (reverse-J shaped) mortality pattern of ash was also observed in Germany (Holzwarth et al., 2013), Norway (Díaz-Yáñez et al., 2020), and Lithuania (Ozolincius et al., 2005).

Similar to our findings ash mortality dramatically increased over time in the Norwegian NFI (Díaz-Yáñez et al., 2020), where mortality almost tripled in trees with the smallest diameters $(5-15 \mathrm{~cm})$ since the arrival of $H$. fraxineus. However, given that the Swiss NFI's sampling threshold is $12 \mathrm{~cm}$, the fivefold increase $(0.4-2 \%)$ in small trees in Switzerland appears even more severe. Our targeted surveys support the mortality model showing strongest increases in mortality in the plots with the smallest trees. Other ash surveys in Europe also revealed increases in ash mortality with increased time since exposure to the fungus, with strongest effects in small trees and saplings, posing challenges for natural forest regeneration (Marçais et al., 2017; Vasaitis and Enderle, 2017; Coker et al., 2019). The disproportional increase in MP of small and slow-growing trees since the arrival of the fungus was hypothesized to be caused by a lack of non-structural carbohydrates (NSC) in these trees (Klesse et al., 2020). A lack of NSCs would lead to lower turgor pressure and smaller earlywood vessels responsible for efficient water transport, reducing photosynthetic rates, the production of defenses, and tree vigor. Nevertheless, our model also showed that MP is still comparatively low in fast-growing small trees (Figure 4). This suggests that not only large healthy trees, but also smaller trees that do not yet show large crown damages should be promoted (Chandelier et al., 2017).

By comparing $A M R$ s and crown damage of ash to that of non-ash trees in the same plots we could show how unusual the increase in mortality and crown damage of ash is. Because of the wide ecological amplitude of F. excelsior (Schlüter, 1967; Keller et al., 1998), its ability to grow on very dry to wet soils, its high drought tolerance (Scherrer et al., 2011; Brinkmann et al., 2016), its climate-growth responses similar to co-occurring species (Čufar et al., 2008; Roibu et al., 2020), and its general wind resistant build-up, we can rule out abiotic factors (such as climate and storm damage) as main factor driving increased mortality. These factors would have likely affected other tree species as well (Figures 1, 3). A similar comparative approach was used in Díaz-Yáñez et al. (2020) using the Norwegian forest inventory. They also showed that the most common co-occurring species spruce, alder, and birch had the same size-dependent mortality rates in the latest inventory interval compared to the two intervals before. Thus, the observed increases in crown damage and mortality rate since 2008 in Switzerland can be most certainly exclusively attributed to the presence of $H$. fraxineus. 


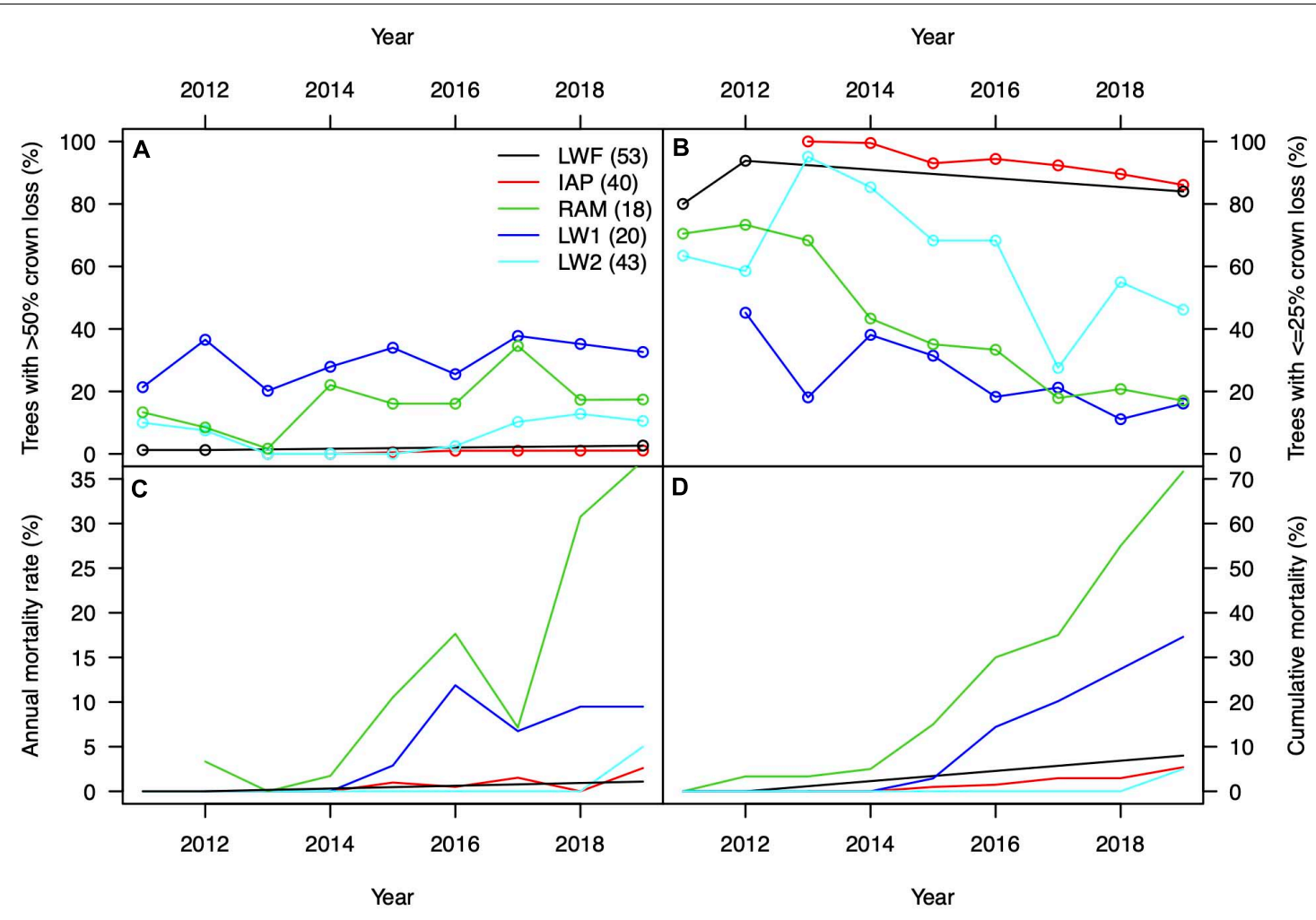

FIGURE 2 | (A) Observed percentage of ash trees with > 50\% crown loss and (B) $\leq 25 \%$ crown loss in the targeted monitoring plots. Numbers in brackets denote the median DBH of monitored trees in the first year of the respective survey. Panel (C) shows annual mortality rate and (D) the cumulative mortality of the monitored trees. In panel (C) data from LWF was excluded, because the monitoring interval was not annual [see circles in panel (A) for actual years of survey]. RAM, LW1, and LW2 are the monitoring plots of the WSL survey.

One of the strongest predictors for MP was the time since the arrival of the fungus in the respective forest district. Even though this variable is a rather coarse estimate for the actual arrival within the permanent sample plot, the significance of the predictor that varied in values from -1 to 11 showed the importance of exposure time in disease severity affecting mortality. The absence of significance of a negative quadratic term of exposure time (TIMESINCE) shows that the disease has not yet reached peak mortality rates, i.e., there is no statistical support for a flattening or even decrease in mortality rates after 10 years of exposure. The continuous design of the Swiss NFI is well positioned to keep track of mortality rates and as such disease severity of ADB (but also any other species-specific damaging agent) on a national level. It would thus be interesting to compare ash mortality rates of the Swiss NFI with other systematic European national forest inventories. Yet, to our knowledge, no such data have been published so far (but see Díaz-Yáñez et al., 2020, for Norway).

\section{Landscape Features Influencing MP}

Our mortality model identified three distinct landscape characteristics positively affecting ADB that have been previously identified in other parts in Europe (Table 1). We found elevated MP in places with higher mean annual precipitation and in wet forest types predominantly belonging to the Alno-Fraxinion group (Keller et al., 1998). These two factors underscore the effect of humid microclimatic conditions favoring fungal sporulation and infection success (Marçais et al., 2016; Enderle et al., 2018). Despite its large ecological amplitude ash only dominates forests of the Alno-Fraxinion group that are considered too wet for F. sylvatica, its main competitor (Professur für Waldbau und Professur für Forstschutz and Dendrologie der ETH Zürich, 1995). This supports previous findings that ash abundance plays also a critical role in the manifestation of disease severity, through increased pathogen infection pressure (Grosdidier et al., 2020). Elevation was found to negatively affect MP, which seems counter-intuitive if elevation is interpreted as a climate proxy. Elevation positively correlates with mean annual precipitation $(r=0.47, p<0.001)$ thereby increasing humidity. Warmer maximum summer temperatures at lower elevation have been shown to be unfavorable or even lethal for the fungus (Hauptman et al., 2013; Grosdidier et al., 2018). We also would rule out elevation effects due to the cold tolerance of $H$. fraxineus, because it has been found to be very resistant to frost (Gross et al., 2014). Therefore, we interpret the negative effect of elevation on MP primarily as the consequence of lower ash abundance and as such lower pathogen infection pressure in higher regions (Supplementary Figure 1). The positive effect of slope steepness on MP in non-wet forest types - already observed before the arrival of 


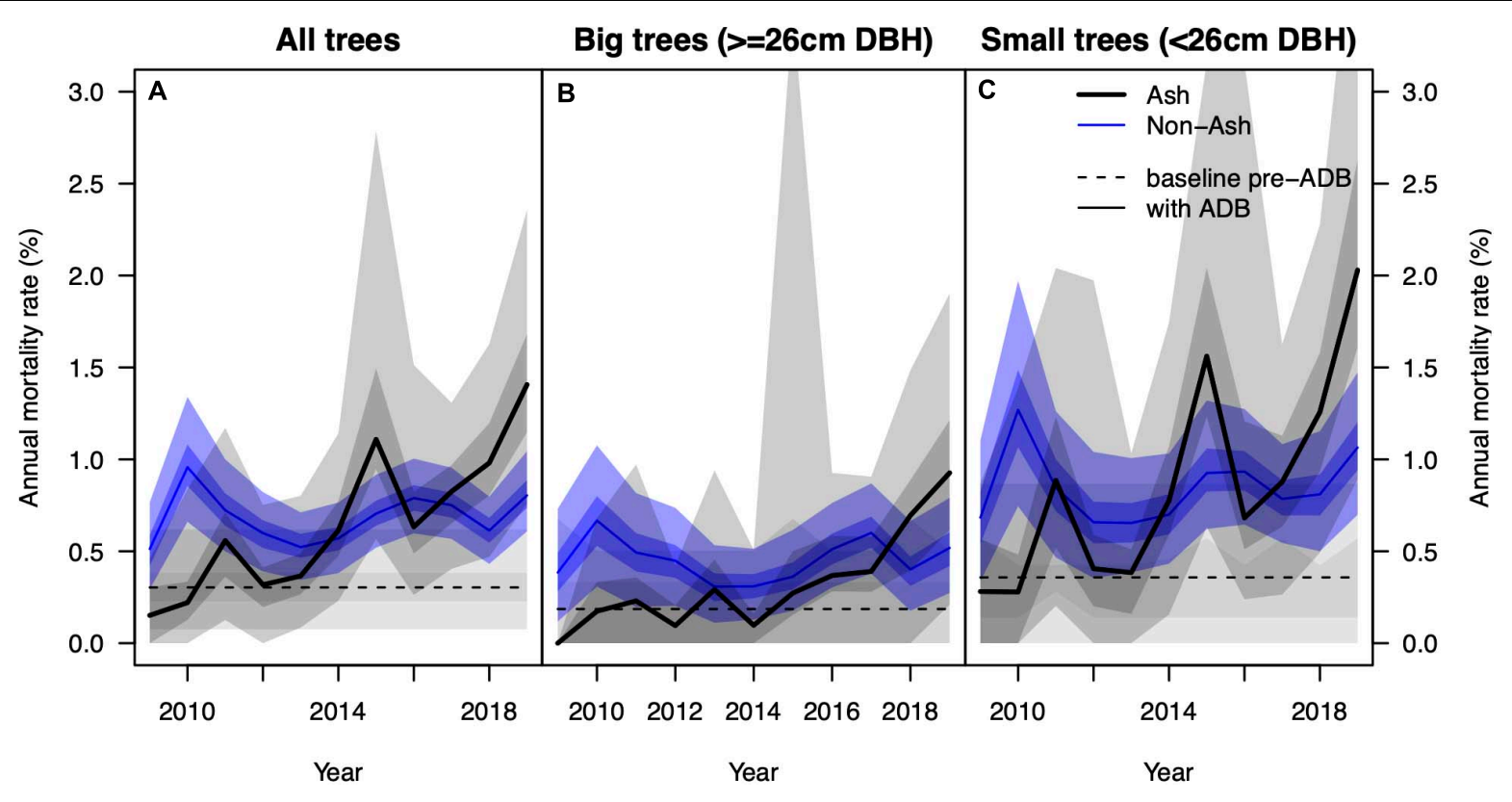

FIGURE 3 | (A) Observed annual mortality rate of ash (solid black line) and non-ash trees (blue line) based on data from the National Forest Inventory. The dashed black line denotes the annual "background" mortality rate before the arrival of the fungus. The shading around the solid lines shows the interquartile range and $95 \%$ confidence interval after 1,000 iterations of resampling with replacement. Panels (B,C) show the same information for big $(\geq 26 \mathrm{~cm}$ DBH) and small trees $(<26 \mathrm{~cm}$ $\mathrm{DBH})$, respectively.

TABLE 1 | Parameters of generalized linear model of mortality probability (MP) based on data of the NFI.

\begin{tabular}{|c|c|c|c|c|c|c|}
\hline \multirow[b]{2}{*}{ Predictors } & \multicolumn{3}{|c|}{ 2009-2019 } & \multicolumn{3}{|c|}{$<2008$} \\
\hline & Log-odds & SE & $p$ & Log-odds & SE & $p$ \\
\hline Intercept & -6.70 & 0.29 & $<0.001$ & -6.13 & 0.25 & $<0.001$ \\
\hline $\log (\mathrm{DBH})$ & -0.65 & 0.11 & $<0.001$ & -0.60 & 0.17 & 0.001 \\
\hline Log(relBAl) & -0.75 & 0.09 & $<0.001$ & -0.76 & 0.13 & $<0.001$ \\
\hline Slope & 0.62 & 0.13 & $<0.001$ & 0.45 & 0.18 & 0.020 \\
\hline Wetness & 0.62 & 0.27 & 0.023 & 0.20 & 0.39 & 0.604 \\
\hline MAP & 0.50 & 0.12 & $<0.001$ & -0.05 & 0.17 & 0.936 \\
\hline Elevation & -0.64 & 0.13 & $<0.001$ & -0.18 & 0.17 & 0.218 \\
\hline TIMESINCE & 0.20 & 0.04 & $<0.001$ & & & \\
\hline Slope $\times$ wetness & -0.67 & 0.23 & 0.004 & -0.24 & 0.34 & 0.522 \\
\hline Observations & \multicolumn{3}{|c|}{1,885} & \multicolumn{3}{|c|}{1,323} \\
\hline
\end{tabular}

In both models all variables except TIMESINCE (time of arrival $=0$, time step $=1$ ) were normalized using mean and variance of the 2009-2018 model. $D B H=$ diameter at breast height, $M A P=$ mean annual precipitation, relBAl= relative annual basal area increment, TIMESINCE = observation year minus year of first fungal presence in forest district. Mean DBH is $30.3 \mathrm{~cm}$, and mean relBAl is $2.97 \%$. Bold-faced numbers indicate significance at $p<0.05$.

H. fraxineus - could be interpreted as generally increased ash mortality at very dry sites.

\section{Probability of Ash Tolerance Against the Pathogen}

Besides the increased mortality rates over the last 2009-2019 period, our analysis also revealed a medium to high proportion of trees with low crown dieback symptoms at the targeted monitoring plots (Figure 2B). Whereas the IAP plots (where $82 \%$ of the trees showed $\leq 25 \%$ crown defoliation in 2019) were specifically chosen to only include trees that were still without symptoms in 2013 and 2014, the abundance of healthy trees in the LWF and LW1 plots (83 and 45\%, respectively) - stands that were not targeted for their healthy trees - is encouraging. This is supported by another national survey in 2018 that revealed widespread occurrence of seemingly tolerant trees across northern Switzerland, with $35 \%$ of trees $\left(N_{\text {treetotal }}=2,990\right.$, $N_{\text {plot }}=144$ ) showing less than $25 \%$ crown defoliation (Queloz, unpublished data).

Landscape features and tree competition are dominant drivers modulating MP, yet, there are clear signs that genetic variability also plays a role in susceptibility to the fungus (Cleary et al., 2017; Kjær et al., 2017). Several studies have now described certain genetic markers associated with higher tolerance against ADB (McKinney et al., 2014; Harper et al., 2016; Havrdová et al., 2016; Sollars et al., 2017; Stocks et al., 2019; Chaudhary et al., 2020; Menkis et al., 2020; Sahraei et al., 2020). Other studies have identified chemical defenses linked to increased fungal resistance, such as leaf (Sambles et al., 2017) or bark metabolites (Villari et al., 2018; Nemesio-Gorriz et al., 2020) that certainly will be associated to genetic variation in the future. Earlier flushing, and earlier leaf-shedding phenotypes also have been found to be more tolerant to the disease (Bakys et al., 2013; Muñoz et al., 2016; Nielsen et al., 2017). Early flushing could desynchronize leaf maturation and fungal sporulation, impeding fungal penetration of a thicker leaf cuticula. However, a drawback of early flushing for ash trees is the increased vulnerability to late frost events (Muñoz et al., 2016). 


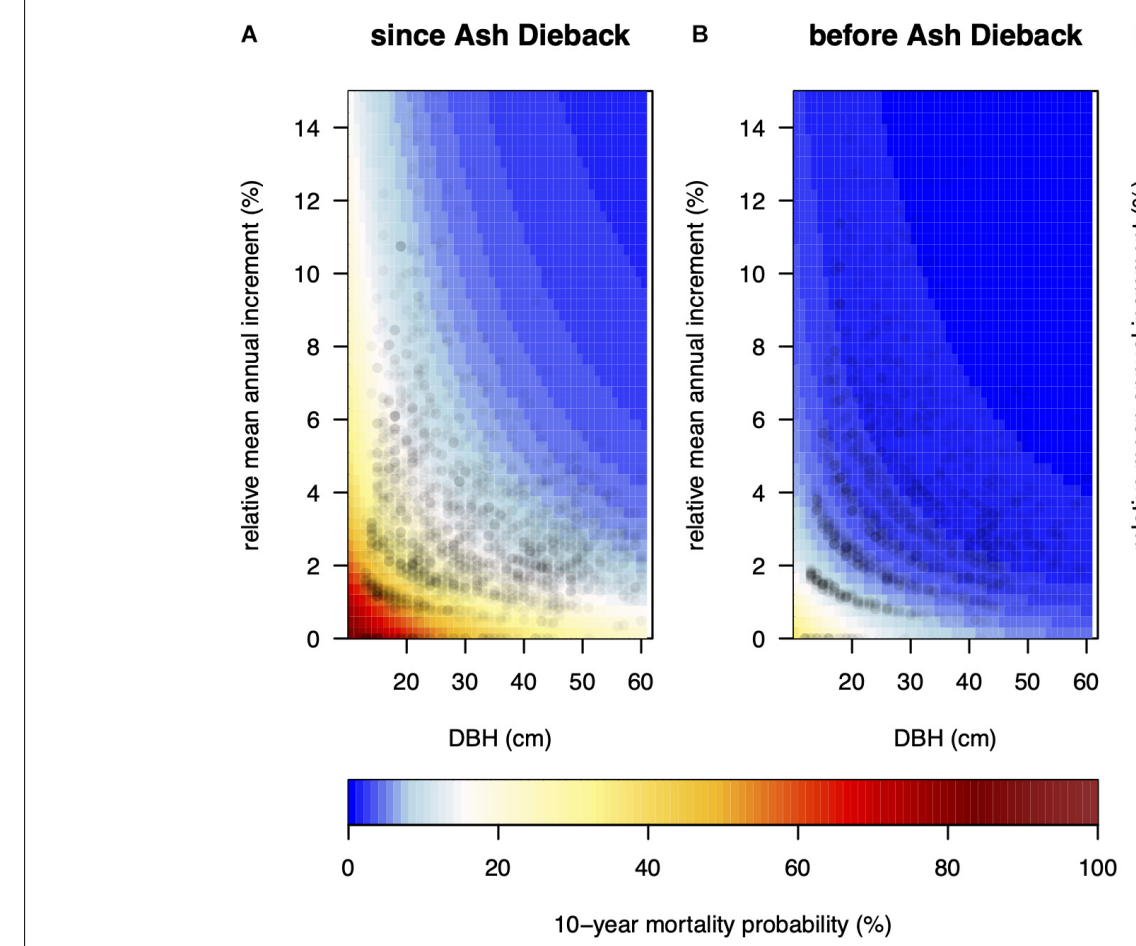

c Probability difference

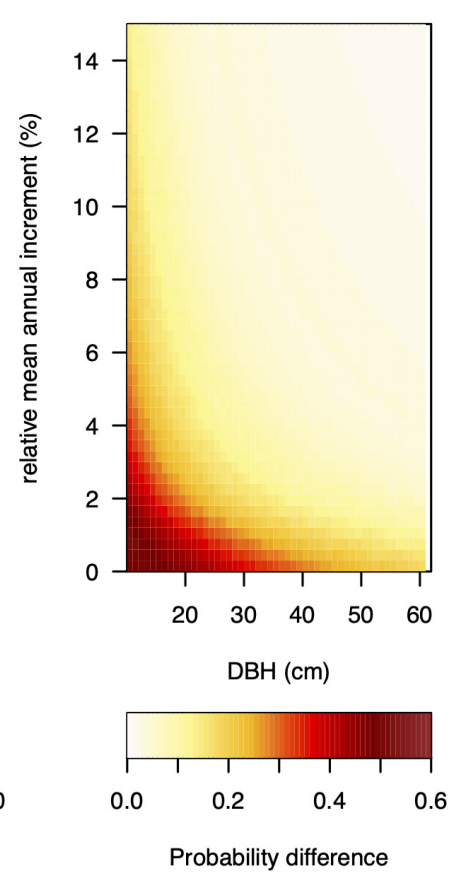

FIGURE 4 | (A) Size and growth-dependent predicted 10-year mortality probability. Fixed variables were set as if the model tree was surveyed in 2019 in a wet forest type, at an elevation of $700 \mathrm{~m}$, slope inclination of 38\%, 1,300 mm mean annual precipitation, and first occurrence of Ash dieback in 2008 (i.e., TIMESINCE = 11). Panel (B) shows the same prediction without year of survey and year of first detection of fungal presence with the model preceding the arrival of the fungus in Switzerland. Panel $\mathbf{( C )}$ displays the difference between panels $(\mathbf{A}, \mathbf{B})$. Points in panels $\mathbf{( A , B )}$ show observed pairs of relative annual basal area increment (relBAl) and diameter at breast height $(\mathrm{DBH})$.

Susceptibility to ADB was found to be strongly negatively correlated to reproductive success under controlled conditions in a clonal field trial (Semizer-Cuming et al., 2019). In contrast, Wohlmuth et al. (2018) did not find a significant relationship between crown damage of adult trees and their saplings in a natural setting, suggesting a complex interaction between environmental conditions and genotypes in controlling $\mathrm{ADB}$ tolerance. Nevertheless, the identification and continuous monitoring of healthy $F$. excelsior seems a simple and straightforward approach for the selection of potentially ADB-tolerant trees to be tested in common garden trials (Menkis et al., 2020). The combined effort of monitoring programs with progeny trials and the everimproving knowledge about genetic and biogeochemical markers related to higher tolerance against the fungus should warrant the long-term survival of $F$. excelsior in Europe.

\section{CONCLUSION}

In this study, we showed that $A M R$ s of $F$. excelsior have drastically increased since the arrival of $H$. fraxineus in Switzerland, and that the increase was disproportionally strong in small and slow-growing trees. For the first time on a national level we quantified which landscape features influence MP, confirming previous research highlighting ash abundance and humidity as primary variables modulating mortality risk. Mortality rates of $F$. excelsior will likely stay high over the coming years in Switzerland. However, on the one hand climate changeinduced warming including more frequent heat waves might disproportionally reduce the vigor of the fungus compared to ash trees. On the other hand, the wide-spread abundance of still healthy trees, especially in northern Switzerland where the fungus has been first reported, gives hope to finding genotypes resistant to the fungus. In the mean-time, promoting healthy ash trees, independent of their size, and reducing air humidity for example through thinning, should be paramount for forestry practitioners to sustain a high population diversity of ash in Europe preserving its reproductive potential for coming decades.

\section{DATA AVAILABILITY STATEMENT}

The data analyzed in this study is subject to the following licenses/restrictions: Swiss NFI data are accessible upon contractual agreement. Pre-processed NFI data (e.g., data for Supplementary Figure 2) can be accessed via www.lfi.ch. For Raw data please contact christoph.fischer@wsl.ch. Non-NFI data will be made available via envidat.ch. 


\section{AUTHOR CONTRIBUTIONS}

SK designed the study with input of $M G, A R$, and VQ. SK performed the analysis and wrote the first draft of the manuscript. $\mathrm{SH}$ provided the IAP data. MA provided the NFI data. All authors commented critically on the manuscript.

\section{FUNDING}

SK was supported by the SwissForestLab (Research Grant SFL-17 P3), and by the Federal Office for the Environment FOEN.

\section{REFERENCES}

Bakys, R., Vasaitis, R., and Skovsgaard, J. P. (2013). Patterns and severity of crown dieback in young even-aged stands of european ash (Fraxinus excelsior L.) in relation to stand density, bud flushing phenotype, and season. Plant Protect. Sci. 49, 120-126. doi: 10.17221/70/2012-PPS

Baral, H.-O., Queloz, V., and Hosoya, T. (2014). Hymenoscyphus fraxineus, the correct scientific name for the fungus causing ash dieback in Europe. IMA Fungus 5, 79-80. doi: 10.5598/imafungus.2014.05.01.09

Bartoń, K. (2018). MuMIn: Multi-Model Inference. R package version 1.42.1.

Bigler, C., and Bugmann, H. (2004). Predicting the time of tree death using dendrochronological data. Ecol. Appl. 14, 902-914. doi: 10.1890/03-5011

Boshier, D., Cordero, J., Harris, S., Pannell, J., Rendell, S., Savill, P., et al. (2005) Ash Species in Europe: Biological Characteristics and Practical Guidelines for Sustainable Use. Oxford: University of Oxford.

Brändle, M., and Brandl, R. (2001). Species richness of insects and mites on trees: expanding Southwood. J. Anim. Ecol. 70, 491-504. doi: 10.1046/j.1365-2656. 2001.00506.x

Brändli, U.-B., Abegg, M., and Allgaier Leuch, B. (2020). Schweizerisches Landesforstinventar. Ergebnisse der vierten Erhebung 2009-2017. Birmensdorf, Eidgenössische Forschungsanstalt für Wald, Schnee und Landschaft. Bern, Bundesamt für Umwelt. Available online at: https: //www.envidat.ch/\#/metadata/schweizerisches-landesforstinventar-2009-2017 (accessed October 12, 2020)

Brinkmann, N., Eugster, W., Zweifel, R., Buchmann, N., and Kahmen, A. (2016) Temperate tree species show identical response in tree water deficit but different sensitivities in sap flow to summer soil drying. Tree Physiol. 36, 1508-1519. doi: 10.1093/treephys/tpw062

Chandelier, A., Delahaye, L., Claessens, H., and Lassois, L. (2017). “Ash dieback in Wallonia, southern Belgium: research on disease development, resistance and management options," in Dieback of European Ash (Fraxinus spp.) Consequences and Guidelines for Sustainable Management, eds R. Vasaitis and R. Enderle (Uppsala: Swedish University of Agricultural Sciences), $53-60$.

Chaudhary, R., Rönneburg, T., Stein Åslund, M., Lundén, K., Durling, M. B. Ihrmark, K., et al. (2020). Marker-trait associations for tolerance to Ash Dieback in Common Ash (Fraxinus excelsior L.). Forests 11:1083. doi: 10.3390/ f11101083

Chira, D., Chira, F., Tãut, I., Popovici, O., Blada, I., Doniţã, N., et al. (2017) "Evolution of ash dieback in Romania," in Dieback of European Ash (Fraxinus spp.) - Consequences and Guidelines for Sustainable Management, eds R. Vasaitis and R. Enderle (Uppsala: Swedish University of Agricultural Sciences), 185-194.

Cleary, M., Nguyen, D., Marčiulynienè, D., Berlin, A., Vasaitis, R., and Stenlid, J. (2016). Friend or foe? Biological and ecological traits of the European ash dieback pathogen Hymenoscyphus fraxineus in its native environment. Sci. Rep. 6, 1-11. doi: 10.1038/srep21895

Cleary, M., Nguyen, D., Stener, L. G., Stenlid, J., and Skovsgaard, J. P. (2017) "Ash and ash dieback in Sweden: a review of disease history, current status, pathogen and host dynamics, host tolerance and management options in forests and landscapes," in Dieback of European Ash (Fraxinus spp.) - Consequences and

\section{ACKNOWLEDGMENTS}

The authors thank Christian Hug, Vivanne Dubach, Sophie Strohecker, and the numerous other people involved in the monitoring programs of LWF, NFI, WSL, and IAP, and Jeanne Portier and Eckehard Brockerhoff for discussion.

\section{SUPPLEMENTARY MATERIAL}

The Supplementary Material for this article can be found online at: https://www.frontiersin.org/articles/10.3389/ffgc.2021. 645920/full\#supplementary-material

Guidelines for Sustainable Management, eds R. Vasaitis and R. Enderle (Uppsala: Swedish University of Agricultural Sciences), 195-208.

Coker, T. L. R., Rozsypálek, J., Edwards, A., Harwood, T. P., Butfoy, L., and Buggs, R. J. A. (2019). Estimating mortality rates of European ash (Fraxinus excelsior) under the ash dieback (Hymenoscyphus fraxineus) epidemic. Plants People Planet 1, 48-58. doi: 10.1002/ppp3.11

Čufar, K., Luis, M. D., Zupančič, M., and Eckstein, D. (2008). A 548-year tree-ring chronology of oak (Quercus spp.) for Southeast Slovenia and its significance as a dating tool and climate archive. Tree Ring Res. 64, 3-15. doi: 10.3959/2007-12.1

Davydenko, K., and Meshkova, V. (2017). "The current situation concerning severity and causes of ash dieback in Ukraine caused by Hymenoscyphus fraxineus," in Dieback of European Ash (Fraxinus spp.) - Consequences and Guidelines for Sustainable Management, eds R. Vasaitis and R. Enderle (Uppsala: Swedish University of Agricultural Sciences), 220-227.

Díaz-Yáñez, O., Mola-Yudego, B., Timmermann, V., Tollefsrud, M. M., Hietala, A. M., and Oliva, J. (2020). The invasive forest pathogen Hymenoscyphus fraxineus boosts mortality and triggers niche replacement of European ash (Fraxinus excelsior). Sci. Rep. 10:5310. doi: 10.1038/s41598-020-61990-4

Eichhorn, J., Roskams, P., Potocic, N., Timmermann, V., Ferretti, M., Mues, V., et al. (2016). "Part IV: visual assessment of crown condition and damaging agents," in Manual on Methods and Criteria for Harmonized Sampling, Assessment, Monitoring, and Analysis of the Effects of Air Pollution on Forests, ed. UNECE ICP Forests Programme Co-ordinating Centre (Eberswalde: Thünen Institute of Forest Ecosystems). Available online at: https://www.icp-forests. org/pdf/manual/2016/ICP_Manual_2017_02_part04.pdf (accessed March 8, 2021).

Enderle, R. (2019). An overview of ash (Fraxinus spp.) and the ash dieback disease in Europe. CAB Rev. 14, 1-12. doi: 10.1079/PAVSNNR201914025

Enderle, R., Metzler, B., Riemer, U., and Kändler, G. (2018). Ash Dieback on sample points of the national forest inventory in South-Western Germany. Forests 9:25. doi: 10.3390/f9010025

Engesser, R., Queloz, V., Meier, F., Kowalski, T., and Holdenrieder, O. (2009). Das Triebsterben der Esche in der Schweiz. Wald und Holz 90, 24-27.

Etzold, S., Waldner, P., Thimonier, A., Schmitt, M., and Dobbertin, M. (2014). Tree growth in Swiss forests between 1995 and 2010 in relation to climate and stand conditions: recent disturbances matter. Forest Ecol. Manag. 311, 41-55. doi: 10.1016/j.foreco.2013.05.040

Fischer, C., and Traub, B. (2019). Swiss National Forest Inventory-Methods and Models of the Fourth Assessment. Cham: Springer International Publishing.

Fortin, M., Bédard, S., DeBlois, J., and Meunier, S. (2008). Predicting individual tree mortality in northern hardwood stands under uneven-aged management in southern Québec, Canada. Ann. Forest Sci. 65, 205-205. doi: 10.1051/forest: 2007088

Ghelardini, L., Migliorini, D., Santini, A., Pepori, A. L., Maresi, G., Vai, N et al. (2017). "From the alps to the apennines: possible spread of ash dieback in Mediterranean areas," in Dieback of European Ash (Fraxinus spp.) Consequences and Guidelines for Sustainable Management, eds R. Vasaitis and R. Enderle (Uppsala: Swedish University of Agricultural Sciences), 140-149.

Gil, W., Kowalski, T., Kraj, W., Zachara, T., Łukaszewicz, J., Paluch, R., et al. (2017). "Ash dieback in Poland - history of the phenomenon and possibilities of its limitation," in Dieback of European Ash (Fraxinus spp.) - Consequences and 
Guidelines for Sustainable Management, eds R. Vasaitis and R. Enderle (Uppsala: Swedish University of Agricultural Sciences), 176-184.

Grosdidier, M., Ioos, R., and Marçais, B. (2018). Do higher summer temperatures restrict the dissemination of Hymenoscyphus fraxineus in France? Forest Pathol. 48:e12426. doi: 10.1111/efp. 12426

Grosdidier, M., Scordia, T., Ioos, R., and Marçais, B. (2020). Landscape epidemiology of ash dieback. J. Ecol. 108, 1789-1799. doi: 10.1111/1365-2745. 13383

Gross, A., Holdenrieder, O., Pautasso, M., Queloz, V., and Sieber, T. N. (2014). Hymenoscyphus pseudoalbidus, the causal agent of European ash dieback. Mol. Plant Pathol. 15, 5-21. doi: 10.1111/mpp.12073

Hanáčková, Z., Havrdová, L., Černy, K., Zahradník, D., and Koukol, O. (2017). Fungal endophytes in ash shoots - diversity and inhibition of Hymenoscyphus fraxineus. Balt. Forestry 23:19.

Harper, A. L., McKinney, L. V., Nielsen, L. R., Havlickova, L., Li, Y., Trick, M., et al. (2016). Molecular markers for tolerance of European ash (Fraxinus excelsior) to dieback disease identified using Associative Transcriptomics. Sci. Rep. 6:19335. doi: 10.1038/srep19335

Hauptman, T., Piškur, B., de Groot, M., Ogris, N., Ferlan, M., and Jurc, D. (2013). Temperature effect on Chalara fraxinea: heat treatment of saplings as a possible disease control method. Forest Pathol. 43, 360-370. doi: 10.1111/efp.12038

Havrdová, L., Novotná, K., Zahradník, D., Buriánek, V., Pešková, V., Šrůtka, P., et al. (2016). Differences in susceptibility to ash dieback in Czech provenances of Fraxinus excelsior. Forest Pathol. 46, 281-288. doi: 10.1111/efp.12265

Heinze, B., Tiefenbacher, H., Litschauer, R., and Kirisits, T. (2017). "Ash dieback in Austria - history, current situation and outlook," in Dieback of European Ash (Fraxinus spp.) - Consequences and Guidelines for Sustainable Management, eds R. Vasaitis and R. Enderle (Uppsala: Swedish University of Agricultural Sciences), 33-52.

Holmes, T. P., Aukema, J. E., Holle, B. V., Liebhold, A., and Sills, E. (2009). Economic impacts of invasive species in forest past, present, and future. Ann. N. Y. Acad. Sci. 1162, 18-38.

Holzwarth, F., Kahl, A., Bauhus, J., and Wirth, C. (2013). Many ways to die partitioning tree mortality dynamics in a near-natural mixed deciduous forest. J. Ecol. 101, 220-230. doi: 10.1111/1365-2745.12015

Hopf, S. (2019). Eschenmonitoring Zustandsbericht 2019. Witterswil: Institut für angewandte Pflanzenbiologie.

Hosmer, D. W. Jr., Lemeshow, S., and Sturdivant, R. X. (2013). Applied Logistic Regression. Hoboken, NJ: John Wiley \& Sons.

Hülsmann, L., Bugmann, H., and Brang, P. (2017). How to predict tree death from inventory data - lessons from a systematic assessment of European tree mortality models. Can. J. Forest Res. 47, 890-900. doi: 10.1139/cjfr-2016-0224

Hülsmann, L., Bugmann, H. K. M., Commarmot, B., Meyer, P., Zimmermann, S., and Brang, P. (2016). Does one model fit all? Patterns of beech mortality in natural forests of three European regions. Ecol. Appl. 26, 2465-2479. doi: 10.1002/eap. 1388

Hultberg, T., Sandström, J., Felton, A., Öhman, K., Rönnberg, J., Witzell, J., et al. (2020). Ash dieback risks an extinction cascade. Biol. Conserv. 244:108516. doi: 10.1016/j.biocon.2020.108516

Keller, W., Wohlgemuth, T., Kuhn, N., Schütz, M., and Wildi, O. (1998). Waldgesellschaften der Schweiz auf floristischer Grundlage. Mitteilungen der Eidgenössischen Forschunganstalt für Wald, Schnee und Landschaft, Vol. 73. Birmensdorf: Eidgenössische Forschungsanstalt für Wald, 269.

Kjær, E. D., McKinney, L. V., Hansen, L. N., Olrik, D. C., Lobo, A., Thomsen, I. M., et al. (2017). "Genetics of ash dieback resistance in a restoration context experiences from Denmark," in Dieback of European Ash (Fraxinus spp.) Consequences and Guidelines for Sustainable Management, eds R. Vasaitis and R. Enderle (Uppsala: Swedish University of Agricultural Sciences), 106-114.

Klesse, S., von Arx, G., Gossner, M. M., Hug, C., Rigling, A., and Queloz, V. (2020). Amplifying feedback loop between growth and wood anatomical characteristics of Fraxinus excelsior explains size-related susceptibility to ash dieback. Tree Physiol. doi: 10.1093/treephys/tpaa091 [Epub ahead of print].

Kowalski, T., and Łukomska, A. (2005). The Studies on Ash Dying (Fraxinus excelsior L.) in the Włoszczowa Forest Unit stands. Available online at: https: //pubag.nal.usda.gov/catalog/5239646 (accessed February 3, 2020).

Lenz, H. D., Bartha, B., Straßer, L., and Lemme, H. (2016). Development of Ash Dieback in South-Eastern Germany and the increasing occurrence of secondary pathogens. Forests 7:41. doi: 10.3390/f7020041
Marçais, B., Husson, C., Caël, O., Dowkiw, A., Delahaye, L., Collet, C., et al. (2017). Estimation of ash mortality induced by Hymenoscyphus fraxineus in France and Belgium. Baltic Forestry 23, 159-167.

Marçais, B., Husson, C., Godart, L., and Caël, O. (2016). Influence of site and stand factors on Hymenoscyphus fraxineus-induced basal lesions. Plant Pathol. 65, 1452-1461. doi: 10.1111/ppa.12542

McKinney, L. V., Nielsen, L. R., Collinge, D. B., Thomsen, I. M., Hansen, J. K., and Kjær, E. D. (2014). The ash dieback crisis: genetic variation in resistance can prove a long-term solution. Plant Pathol. 63, 485-499. doi: 10.1111/ppa. 12196

McKinney, L. V., Thomsen, I. M., Kjær, E. D., Bengtsson, S. B. K., and Nielsen, L. R. (2012). Rapid invasion by an aggressive pathogenic fungus (Hymenoscyphus pseudoalbidus) replaces a native decomposer (Hymenoscyphus albidus): a case of local cryptic extinction? Fungal Ecol. 5, 663-669. doi: 10.1016/j.funeco.2012. 05.004

Menkis, A., Bakys, R., Stein Åslund, M., Davydenko, K., Elfstrand, M., Stenlid, J., et al. (2020). Identifying Fraxinus excelsior tolerant to ash dieback: visual field monitoring versus a molecular marker. Forest Pathol. 50:e12572. doi: 10.1111/ efp. 12572

MeteoSwiss (2021). Spatial Climate Analyses. Available online at: https://www.meteoswiss.admin.ch/home/climate/swiss-climate-in-detail/ raeumliche-klimaanalysen.html (accessed February 15, 2021)

Mitchell, R. J., Beaton, J. K., Bellamy, P. E., Broome, A., Chetcuti, J., Eaton, S., et al. (2014). Ash dieback in the UK: a review of the ecological and conservation implications and potential management options. Biol. Conserv. 175, 95-109. doi: 10.1016/j.biocon.2014.04.019

Moser, W. K., Barnard, E. L., Billings, R. F., Crocker, S. J., Dix, M. E., Gray, A. N., et al. (2009). Impacts of nonnative invasive species on US forests and recommendations for policy and management. J. Forestry 107, 320-327.

Muñoz, F., Marçais, B., Dufour, J., and Dowkiw, A. (2016). Rising out of the ashes: additive genetic variation for crown and collar resistance to Hymenoscyphus fraxineus in Fraxinus excelsior. Phytopathology 106, 1535-1543. doi: 10.1094/ PHYTO-11-15-0284-R

Nemesio-Gorriz, M., Menezes, R. C., Paetz, C., Hammerbacher, A., Steenackers, M., Schamp, K., et al. (2020). Canditate metabolites for ash dieback tolerance in Fraxinus excelsior. J. Exp. Bot. 71, 6074-6083. doi: 10.1093/jxb/eraa306

Nielsen, L. R., Mckinney, L. V., and Kjær, E. D. (2017). Host phenological stage potentially affects dieback severity after Hymenoscyphus fraxineus infection in Fraxinus excelsior seedlings. Baltic Forestry 23, 229-232.

Ozolincius, R., Miksys, V., and Stakenas, V. (2005). Growth-independent mortality of Lithuanian forest tree species. Scand. J. Forest Res. 20, 153-160. doi: 10.1080/ 14004080510042164

Pautasso, M., Aas, G., Queloz, V., and Holdenrieder, O. (2013). European ash (Fraxinus excelsior) dieback - A conservation biology challenge. Biol. Conserv. 158, 37-49. doi: 10.1016/j.biocon.2012.08.026

Pautasso, M., Schlegel, M., and Holdenrieder, O. (2015). Forest health in a changing world. Microb. Ecol. 69, 826-842. doi: 10.1007/s00248-014-0545-8

Professur für Waldbau und Professur für Forstschutz and Dendrologie der ETH Zürich (1995). Mitteleuropäische Waldbaumarten. Artbeschreibung und Ökologie unter besonderer Berücksichtigung der Schweiz. Zürich. Available online at: https:/ethz.ch/content/dam/ethz/special-interest/ usys/ites/waldmgmt-waldbau-dam/documents/Lehrmaterialien/Skripte/ Baumartenbeschreibungen/ME-Waldbaumarten (accessed October 29, 2020).

Pyšek, P., and Richardson, D. M. (2010). Invasive species, environmental change and management, and health. Annu. Rev. Environ. Resour. 35, 25-55. doi: 10.1146/annurev-environ-033009-095548

Queloz, V., and Gossner, M. M. (2019). Zukunft der Esche - zwei neue Projekte an der WSL. Waldschutz aktuell 3. Available online at: https://www.dora.lib4ri.ch/ wsl/islandora/object/wsl\%3A21870/datastream/PDF/Queloz-2019-Zukunft_ der_Esche_\%E2\%80\%93_zwei-\%28published_version\%29.pdf (accessed October 7, 2020)

Queloz, V., Hopf, S., Schoebel, C. N., Rigling, D., and Gross, A. (2017). "Ash dieback in Switzerland: history and scientific achievements," in Dieback of European Ash (Fraxinus spp.) - Consequences and Guidelines for Sustainable Management, eds R. Vasaitis and R. Enderle (Uppsala: Swedish University of Agricultural Sciences), 68-78.

R Core Team (2018). R: A Language and Environment for Statistical Computing. Vienna: R Foundation for Statistical Computing. 
Rigling, D., Hilfiker, S., Schöbel, C., Meier, F., Engesser, R., Scheidegger, C., et al. (2016). Das Eschentriebsterben. Biologie, Krankheitssymptome und Handlungsempfehlungen. Birmensdorf: Eidg. Forschungsanstalt WSL.

Roibu, C.-C., Sfeclã, V., Mursa, A., Ionita, M., Nagavciuc, V., Chiriloaei, F., et al. (2020). The climatic response of tree ring width components of ash (Fraxinus excelsior L.) and common oak (Quercus robur L.) from Eastern Europe. Forests 11:600. doi: 10.3390/f11050600

Sahraei, S. E., Cleary, M., Stenlid, J., Brandström Durling, M., and Elfstrand, M. (2020). Transcriptional responses in developing lesions of European common ash (Fraxinus excelsior) reveal genes responding to infection by Hymenoscyphus fraxineus. BMC Plant Biol. 20:455. doi: 10.1186/s12870-020-02656-1

Sambles, C. M., Salmon, D. L., Florance, H., Howard, T. P., Smirnoff, N., Nielsen, L. R., et al. (2017). Ash leaf metabolomes reveal differences between trees tolerant and susceptible to ash dieback disease. Sci. Data 4:170190. doi: 10.1038/ sdata. 2017.190

Scherrer, D., Bader, M. K.-F., and Körner, C. (2011). Drought-sensitivity ranking of deciduous tree species based on thermal imaging of forest canopies. Agric. Forest Meteorol. 151, 1632-1640. doi: 10.1016/j.agrformet.2011.06.019

Schlüter, H. (1967). Buntlaubhölzer in kollinen Waldgesellschaften Mittelthüringens. Die Kulturpflanze 15, 115-138. doi: 10.1007/BF02095708

Schreuder, H. T., Hansen, M., and Kohl, M. (1999). Relative costs and benefits of a continuous and a periodic forest inventory in Minnesota. Environ. Monit. Assess. 59, 135-144. doi: 10.1023/A:1006137914405

Semizer-Cuming, D., Finkeldey, R., Nielsen, L. R., and Kjær, E. D. (2019). Negative correlation between ash dieback susceptibility and reproductive success: good news for European ash forests. Ann. Forest Sci. 76:16. doi: 10.1007/s13595-0190799-x

Sheil, D., and May, R. M. (1996). Mortality and recruitment rate evaluations in heterogeneous tropical forests. J. Ecol. 84, 91-100. doi: 10.2307/2261703

Sollars, E. S. A., Harper, A. L., Kelly, L. J., Sambles, C. M., Ramirez-Gonzalez, R. H., Swarbreck, D., et al. (2017). Genome sequence and genetic diversity of European ash trees. Nature 541, 212-216. doi: 10.1038/nature20786

Stahel, W. (2019). regr0: Building Regression Models. Available online at: https://R-Forge.R-project.org/projects/regdevelop/ (accessed July 10, 2020).
Stocks, J. J., Metheringham, C. L., Plumb, W., Lee, S. J., Kelly, L. J., Nichols, R. A., et al. (2019). Genomic basis of European ash tree resistance to ash dieback fungus. bioRxiv [Preprint] doi: 10.1101/626234

Trumbore, S., Brando, P., and Hartmann, H. (2015). Forest health and global change. Science 349, 814-818. doi: 10.1126/science.aac6759

Vasaitis, R., and Enderle, R. (2017). "Dieback of European ash (Fraxinus spp.) consequences and guidelines for sustainable management," in Dieback of European ash (Fraxinus spp.) - Consequences and Guidelines for Sustainable Management, eds R. Vasaitis and R. Enderle (Uppsala: Swedish University of Agricultural Sciences).

Villari, C., Dowkiw, A., Enderle, R., Ghasemkhani, M., Kirisits, T., Kjær, E. D., et al. (2018). Advanced spectroscopy-based phenotyping offers a potential solution to the ash dieback epidemic. Sci. Rep. 8:17448. doi: 10.1038/s41598-018-35770-0

Wohlmuth, A., Essl, F., and Heinze, B. (2018). Genetic analysis of inherited reduced susceptibility of Fraxinus excelsior L. seedlings in Austria to ash dieback. Forestry (Lond.) 91, 514-525. doi: 10.1093/forestry/cpy012

Wolf, A., Møller, P. F., Bradshaw, R. H. W., and Bigler, J. (2004). Storm damage and long-term mortality in a semi-natural, temperate deciduous forest. Forest Ecol. Manag. 188, 197-210. doi: 10.1016/j.foreco.2003.07.009

Wunder, J., Brzeziecki, B., Żybura, H., Reineking, B., Bigler, C., and Bugmann, H. (2008). Growth-mortality relationships as indicators of life-history strategies: a comparison of nine tree species in unmanaged European forests. Oikos 117, 815-828. doi: 10.1111/j.0030-1299.2008.16371.x

Conflict of Interest: The authors declare that the research was conducted in the absence of any commercial or financial relationships that could be construed as a potential conflict of interest.

Copyright (c) 2021 Klesse, Abegg, Hopf, Gossner, Rigling and Queloz. This is an open-access article distributed under the terms of the Creative Commons Attribution License (CC BY). The use, distribution or reproduction in other forums is permitted, provided the original author(s) and the copyright owner(s) are credited and that the original publication in this journal is cited, in accordance with accepted academic practice. No use, distribution or reproduction is permitted which does not comply with these terms. 